\title{
ANALISIS TINGKAT PENDAPATAN DAN KESEJAHTERAAN PETANI KELAPA KELAPA SAWIT DI DESA MERARAI SATU KECAMATAN SUNGAI TEBELIAN KABUPATEN SINTANG
}

\author{
ANALYSIS OF INCOME AND WELFARE FARMER PALM OIL \\ IN DESA MERARAI SATU KECAMATAN SUNGAI TEBELIAN KABUPATEN SINTANG
}

Firman, Adi Suyatno, dan Dewi Kurniati

Program Studi Agribisnis Fakultas Pertanian Universitas Tanjungpura

Jln. Prof. Dr. Hadari Nawawi, Pontianak, 78124, Indonesia.

email: laza_bran@yahoo.com

\begin{abstract}
ABSTRAK
Kelapa kelapa sawit merupakan salah satu komoditas ekspor non migas yang mempunyai nilai ekonomi dalam perdagangan nasional maupun internasional. Pesatnya perkembangan perkebunan kelapa kelapa sawit di Kalimantan Barat tidak dipungkiri turut mendongkrak perekonomian di Kalimantan Barat. PT. SDK III (SDK III) yang beroperasi di Desa Merarai Satu kecamatan Sungai Tebelian Kabupaten Sintang. PT. SDK III adalah perusahaan yang mengacu pada pola pengembangan perkebunan inti rakyat dikaitkan dengan program pengembangan transmigrasi (PIR-Trans). Tujuan dari penelitian ini adalah untuk mengetahui Tingkat pendaptan dan kesejahteraan petani kelapa kelapa sawit di Desa Merarai Satu Kecamatan Sungai Tebelian Kabupaten Sintang. Dari perhitungan uji t tingkat pendapatan petani kelapa kelapa sawit setelah lunas kredit lebih tinggi dibandingkan sebelum lunas kredit petani kelapa kelapa sawit terhadap PT. SDK III hal ini dapat dilihat pada uji-t diperoleh $\mathrm{t}$ hitung $>\mathrm{t}$ tabel yaitu sebesar 12,245 dan $\mathrm{t}$ tabel pada 0,05 sebesar 2,708 yang artinya tolak $\mathrm{H} 0$ dan terima $\mathrm{H} 1$.

Tingkat kesejahteraan petani kelapa kelapa sawit sebelum dan setelah lunas kredit diukur dengan menggunakan indikator tingkat kesejahteraan setara beras (Sajogyo) dimana sebelum lunas kredit petani kelapa kelapa sawit di Desa Merarai Satu termasuk dalam kriteria cukup dimana terdapat $32 \mathrm{KK}$ atau sebesar $80 \%$ KK petani kelapa kelapa sawit sedangkan setelah lunas kredit petani kelapa kelapa sawit Di Desa Merarai Satu termasuk dalam kriteria kaya yaitu sebanyak $28 \mathrm{kk}$ atau $70 \%$ petani kelapa kelapa sawit. Dari pendapatan setara beras dapat disimpulkan bahwa petani kelapa kelapa sawit di Desa Merarai Satu dapat dikatakan sejahtera.
\end{abstract}

Kata kunci : Tingkat Pendapatan, Kesejahteraan, Petani Kelapa Kelapa sawit

\section{ABSTRACT}

Oil palm is one of the non-oil export commodities which have economic value in national and international trade. The rapid development of oil palm plantations in West Kalimantan no doubt helped boost the economy in West Kalimantan. Sintang has many palm oil plantation company that operates one of which is PT. Sinar Dinamika Kapuas III (SDK III) operating in Desa Merarai Satu Kecamatan Sungai Tebelian Kabupaten Sintang. PT. SDK III is to the pattern of the nucleus estate 
development people associated with the development of transmigration program (PIR - Trans). The purpose of this study was to determine the level of income of oil palm farmers and prosperity in Desa Merarai Satu Kecamatan Sungai Tebelian Kabupaten Sintang. Of calculation t test oil palm farmers' income in Desa merarai Satu after the loan is paid off is higher than before the loan is paid off by the farmers against PT. SDK III of this can be seen on the t-test obtained t arithmetic greater than t table that is equal to 12.245 and t table at 0.05 at 2.708 , which means $\mathrm{HO}$ rejected and $\mathrm{HI}$ accepted.

Oil palm farmers' welfare level before and after the loan is paid off is measured using indicators of the level of welfare rice equivalent ( Sajogyo) where before the credit is paid off oil palm farmers in the village Merarai One included in the criteria enough where there are 32 households or $80 \%$ of households, while oil palm farmers after credit hull oil palm farmers in the village included in the criteria Merarai One rich as many as 28 households or $70 \%$ of oil palm farmers. Of revenue can be concluded that the rice equivalent oil palm farmers in the village Merarai One can be said prosper.

Keywords : Income level, Welfare, Oil Palm Farmers

\section{PENDAHULUAN}

Pembangunan pertanian bertujuan untuk meningkatkan pendapatan dan kesejahteraan petani melalui peningkatan produksi pertanian. Peningkatan produksi pertanian ini selain untuk memenuhi bahan baku industri di dalam negeri yang terus berkembang juga bertujuan untuk meningkatkan devisa dari ekspor hasil pertanian. Adapun salah satu langkah yang dapat dilakukan untuk meningkatkan kontribusi subsektor pertanian ini adalah dengan produksi tanaman perkebunan (Soekanda, 2001). Salah satu jenis tanaman perkebunan yang hasilnya diekspor dan saat ini menyumbang kontribusi yang cukup besar dalam perolehan devisa negara adalah komoditi kelapa kelapa sawit.

Kelapa kelapa sawit bukanlah tanaman asli Indonesia, namun kenyataannya kelapa kelapa sawit mampu hadir dan berkiprah di Indonesia tumbuh dan berkembang dengan baik dan produk olahannya, misalnya minyak kelapa sawit. Minyak kelapa sawit atau yang dikenal juga istilah CPO (Crude Palm Oil) saat ini menjadi salah satu komoditas perkebunan yang handal. Adapun wilayah Sintang merupakan salah satu kabupaten yang berpotensi sebagai pengembangan komoditi kelapa kelapa sawit di Kalimantan Barat menurut data Badan Pusat Statistik Kalimantan Barat (2013). hampir di setiap kabupaten/kota di Kalimantan Barat telah dibuka perkebunan kelapa kelapa sawit. di Kabupaten Sintang kelapa kelapa sawit merupakan komoditi unggulan selain karet. Di Kabupaten Sintang perkebunan besar memproduksi 59.729 ton kelapa kelapa sawit dan dengan luas lahan 73.557 ha. Di perkebunan rakyat Kabupaten Sintang memproduksi 56.940 ton dengan luas lahan 30.406 ha.

Berdasarkan informasi yang ada, di Kabupaten Sintang sudah banyak perusahaan perkebunan kelapa kelapa sawit yang beroperasi salah satunya adalah PT. SDK III (SDK III) yang beroperasi di Desa Merarai Satu kecamatan Sungai Tebelian Kabupaten Sintang. PT. SDK III adalah perusahaan swasta nasional yang bergerak di bidang perkebunan kelapa kelapa sawit dengan mengacu pada pola pengembangan perkebunan inti rakyat yang dikaitkan dengan program pengembangan transmigrasi (PIR-Trans).

Adanya perkebunan kelapa kelapa sawit ini banyak membawa perubahan dalam kehidupan petani yang ada di sekitarnya. Sebagian masyarakat berubah mata pencariannya dari petani biasa yaitu berladang pindah-pindah menjadi petani kelapa kelapa sawit atau pun buruh perkebunan kelapa kelapa sawit dikarenakan para petani yang telah menjadi petani peserta mendapatkan jatah kebun kelapa kelapa sawit dari perusahaan dengan sistem kredit selama 8 tahun, yaitu dari tahun 2003 sampai tahun 2010 dengan potongan kredit sebesar 30\% dari pendapatan petani per bulan dimana setiap petani peserta 
mendapatkan kebun seluas 2 ha per petani. Berdasarkan uraian diatas maka peneliti tetarik untuk meneliti :

Bagaimana tingkat pendapatan petani kelapa kelapa sawit Desa Merarai Satu Kecamatan Sungai Tebelian Kabupaten Sintang dan bagaimana tingkat kesejahteraan petani kelapa kelapa sawit Desa Merarai Satu Kecamatan Sungai Tebelian Kabupaten Sintang. Adapun tujuan penelitian ini adalah untuk mengetahui Tingkat pendaptan petani kelapa kelapa sawit di Desa Merarai Satu Kecamatan Sungai Tebelian Kabupaten Sintang dan tingkat kesejahteraan petani kelapa kelapa sawit di Desa Merarai Satu Kecamatan Sungai Tebelian Kabupaten Sintang.

Penelitian ini dapat menjadi informasi bagi masyarakat dan pemerintah mengenai tingkat pendapatan dan kesejahteraan petani kelapa kelapa sawit Desa Merarai Satu Kecamatan Sungai Tebelian Kabupaten Sintang.

\section{BAHAN DAN METODE}

Penelitian ini dilakukan dengan metode survei. Lokasi penelitian dipilih secara sengaja (purposive), yaitu desa Merarai satu, Kecamatan Sungai Tebelian Kabupaten Sintang. Penelitian dilaksanakan berlangsung 2 bulan. Lokasi ini dipilih dengan alasan bahwa daerah ini merupakan daerah tempat beroperasinya perusahaan kelapa kelapa sawit PT. Sinar Dinamika Kapuas (PT. SDK) III. Dalam penelitian ini sampel yang diambil berjumlah $40 \mathrm{kk}$ dari $800 \mathrm{kk}$ petani kelapa kelapa sawit yang ada di desa tersebut. Data yang dikumpulkan dalam penelitian ini adalah data primer dan data sekunder. Data primer diperoleh dari pengamatan dan wawancara langsung dengan petani contoh dengan menggunakan kuisioner sebagai tuntutan pertanyaan. Data sekunder diperoleh dari lembaga atau instansi yang terkait seperti PT. SDK III, Dinas Perkebunan dan untuk literatur diperoleh dari buku dan jurnal yang berkaitan dengan penelitian.

Untuk mengukur pendapatan petani kelapa kelapa sawit sebelum dan setelah lunas kredit pada PT. SDK III, dapat digunakan rumus Uji t yaitu $t=\left|\frac{X_{1}-X_{2}}{S X_{1}-X_{2}}\right|$

Dimana :

$$
\begin{aligned}
\mathrm{T}= & \text { Nilai Hitung } \\
\overline{\mathrm{X}}_{1}= & \text { Rata }- \text { rata pendapatan } \\
& \text { Petani setelah lunas kredit } \\
& \text { pada PT. SDK III. } \\
\overline{\mathrm{X}}_{2}= & \text { Rata }- \text { rata pendapatan } \\
& \text { Petani sebelum lunas kredit } \\
& \text { pada PT. Sinar Dinamika } \\
& \text { Kapuas III } \\
\mathrm{SX}_{1}-\mathrm{X}_{2}= & \text { standar eror berbeda }
\end{aligned}
$$

Selanjutnya untuk mencari $\overline{\mathrm{X}}_{1}$ dan $\overline{\mathrm{X}}_{2}$ yaitu:

$$
\overline{\mathrm{X}}_{1}=\frac{\Sigma X_{1}}{\mathrm{n}_{1}} \quad \overline{\mathrm{X}}_{2}=\frac{\Sigma X_{2}}{\mathrm{n}_{2}}
$$

Untuk mencari jumlah kuadarat (SS) dapat digunakan rumus sebagai berikut:

$$
\begin{aligned}
& \mathrm{SS}_{1}=\Sigma \mathrm{X}_{1}^{2}-\left(\frac{\Sigma X_{1}}{\mathrm{n}_{1}}\right)^{2} \\
& \mathrm{SS}_{2}=\Sigma \mathrm{X}_{2}^{2}-\left(\frac{\Sigma X_{2}}{\mathrm{n}_{2}}\right)
\end{aligned}
$$

Dimana :

$\mathrm{SS}_{1}=$ Jumlah kuadrat pendapatan masyarakat setelah lunas kredit pada PT. SDK III

$\mathrm{SS}_{2}=$ Jumlah kuadrat pendapatan masyarakat sebelum lunas kredit pada PT. SDK III

Dan untuk mengetahui standar error beda dapat digunakan rumus sebagai berikut:

$$
\mathrm{Sx}_{1}-\mathrm{x}_{2}=\sqrt{\frac{S S_{1}+S S_{2}}{\mathrm{n}_{1}+\mathrm{n}_{2}-2}\left(\frac{1}{\mathrm{n}_{1}}+\frac{1}{\mathrm{n}_{2}}\right)}
$$

Dimana :

$\mathrm{n}_{1}=$ Jumlah sampel sebelum lunas kredit pada PT. SDK III

$\mathrm{n}_{2}=$ Jumlah sampel setelah lunas kredit pada PT. SDK III

Berdasarkan kriteria Uji t, maka dapat ditentukan sebagai berikut: 
a. Jika t-hitung $<$ t-tabel, berarti terima $\mathrm{H}_{\mathrm{o}}$, tolak $\mathrm{H}_{1}$

b. Jika t-hitung $\geq$ t-tabel, berarti tolak $\mathrm{H}_{\mathrm{o}}$, terima $\mathrm{H}_{1}$

$$
\mathrm{H}_{0}: \mu_{1}=\mu_{2}
$$

Artinya: tidak ada perbedaan pendapatan antara sesudah dan sebelum lunas kredit pada PT. SDK III.

$$
\mathrm{H}_{1}: \mu_{1} \neq \mu_{2}
$$

Artinya: ada perbedaan pendapatan sebelum dan sesudah lunas kredit pada PT. SDK III.

Untuk mengetahui tingkat kesejahteraan petani diukur berdasarkan pendapatan setara beras pertahun. Analisis yang digunakan adalah analisis setara beras menurut Sajogyo (1982), yaitu sebagai berikut :

1. Paling Miskin Kriteria $=<240 \mathrm{Kg}$ Beras/Kapita/Tahun

2. Miskin Sekali Kriteria $240 \mathrm{Kg}-360 \mathrm{Kg}$ Beras/Kapita/Tahun

3. Miskin Kriteria $360 \mathrm{Kg}-480 \mathrm{Kg}$ Beras/Kapita/Tahun
4. Cukup Dengan Kriteria $480 \mathrm{Kg}-960 \mathrm{Kg}$ Beras/Kapita/Tahun

5. Kaya Dengan Kriteria > $980 \mathrm{Kg}$ Beras /Kapita/Tahun

\section{HASIL DAN PEMBAHASAN}

\section{Analisis Pendapatan Petani}

Total biaya tetap yang dikeluarkan oleh petani kelapa kelapa sawit desa merarai satu sebelum lunas kredit rata-rata sebesar $\mathrm{Rp}$ $526.631,25(1,79 \%)$ per petani per tahun per hektar yang lebih kecil dari biaya tetap yang dikeluarkan setelah lunas kredit yaitu sebesar Rp 630.733,33 (5,20\%) per petani per tahun per hektar hal ini dikarenakan pajak atas lahan perkebuanan masih menjadi tanggungjawab perusahaan. Total biaya tidak tetap sebelum lunas kredit rata-rata adalah sebesar $\mathrm{Rp}$ 28.762.470 $(98,20 \%)$ per petani per tahun per hektar sedangkan pada saat setelah lunas kredit total biaya tidak tetap rata-rata sebesar $\mathrm{Rp}$ 11.494.309 $(94,79 \%)$ per petani per tahun per hektar untuk lebih jelah dapat dilihat pada Tabel

Tabel 1. Pendapatan Petani Kelapa Kelapa sawit Sebelum dan Setelah Lunas Kredit (orang/th/ha)

\begin{tabular}{lcc}
\hline \multicolumn{1}{c}{ Uraian } & Sebelum Lunas Kredit & Setelah Lunas Kredit \\
\hline Penerimaan & & \\
Produksi TBS (Kg) & $34.298,8$ & 36.783 \\
Harga TBS (Rp)/Kg & 1.800 & 1.900 \\
Total penerimaan & 61.737 .840 & 69.887 .700 \\
\hline Biaya (Rp) & $526.631,2528.762 .470$ & $630.733,33$ \\
Biaya tetap & $29.289 .101,25$ & 11.494 .309 \\
Biaya tidak tetap & $32.448 .738,75$ & $12.125 .042,33$ \\
Total biaya (Rp) & & $57.762 .657,67$ \\
\hline Total pendapatan $(\mathrm{Rp})$ & &
\end{tabular}

Penerimaan petani kelapa kelapa sawit sebelum lunas kredit adalah Rp 61.737.840 per petani per tahun dan Setelah lunaas kredit adalah Rp 69.887.700 per petani per tahun per hektar. total biaya yang dikeluarkan petani kelapa kelapa sawit sebelum lunas kredit adalah rata-rata sebesar Rp 29.289.101,75 per petani per tahun per hektar dan total biaya setelah lunas kredit adalah Rp 12.125.042,33 per petani per tahun per hektar. Pendapatan rata-rata petani kelapa kelapa sawit sebelum lunas kredit adalah sebesar Rp 32.448.783,75 
per petani per tahun per hektar Sedangkan setelah lunas kredit adalah Rp 57.762.657,67 per petani per tahun per hektar.

Berdasarkan uji statistik yang dilakukan menggunakan spss 16 yaitu dapat diketahui bahwa nilai $\mathrm{t}$ hitung sebesar 12,245 dan t tabel pada 0,05 sebesar 2,708 atau nilai $t$ hitung $>t$ tabel yang artinya bahwa tolak $\mathrm{H} 0$ dan diterima $\mathrm{H} 1$ yaitu terdapat perbedaan yang signifikan antara pendapatan petani kelapa kelapa sawit di desa Merarai Satu sebelum dan setelah lunas kredit terhadap PT. SDK III.
Dapat disimpulkan bahwa pendapatan setelah lunas kredit petani kelapa kelapa sawit desa merari satu lebih besar dibandingkan sebelum lunas kredit.

\section{Tingkat Kesejahteraan Petani}

Berdasarkan penelitian yang dilakukan, tingkat kesejahteraan setara beras (kg/kapita/tahun) petani kelapa kelapa sawit sebelum dan setelah lunas kredit dapat dilihat pada tabel 2 .

Tabel 2. Tingkat Kesejahteraan Setara Beras Sebelum dan Setelah Lunas Kredit

\begin{tabular}{lcccc}
\hline \multirow{2}{*}{$\begin{array}{c}\text { Kriteria tingkat kesejahteraan } \\
\text { responden }\end{array}$} & \multicolumn{4}{c}{ Jumlah responden (KK) } \\
\cline { 2 - 5 } & $\begin{array}{c}\text { Sebelum } \\
\text { lunas kredit }\end{array}$ & $\begin{array}{c}\text { Persentase } \\
(\%)\end{array}$ & $\begin{array}{c}\text { Setelah } \\
\text { lunas kredit }\end{array}$ & $\begin{array}{c}\text { Persentase } \\
(\%)\end{array}$ \\
\hline Paling miskin $<240 \mathrm{Kg}$ & - & - & - & - \\
Miskin sekali $240-360 \mathrm{Kg}$ & - & - & - & - \\
Miskin 360 $-480 \mathrm{Kg}$ & 2 & 5 & - & - \\
Cukup 480-960 Kg & 32 & 80 & 12 & 30 \\
Kaya $>960 \mathrm{Kg}$ & 6 & 15 & 28 & 70 \\
\hline Jumlah & 40 & 100 & 40 & 100 \\
\hline
\end{tabular}

Dari Tabel 2 dapat diketahui bahwa penadapatan setara beras per kilogram per kapita per tahun sebelum lunas kredit petani kelapa kelapa sawit desa merarai satu kecamatan sungai tebelian kabupaten sintang termasuk dalam kriteria cukup dimana terdapat $32 \mathrm{KK}$ atau sebesar $80 \%$ KK petani kelapa kelapa sawit termasuk dalam kriteria cukup, selebih nya termasuk dalam kriteria miskin dan kaya yaitu sebanyak $2 \mathrm{KK}$ atau $5 \% \mathrm{KK}$ petani kelapa kelapa sawit yang termasuk dalam kriteria miskin serta $8 \mathrm{KK}$ atau $15 \%$ termasuk dalam kriteria kaya. sedangkan setelah petani kelapa kelapa sawit lunas kredit dengan kriteria pendapatan setara beras $>960$ $\mathrm{Kg} / \mathrm{kapita} /$ tahun yaitu sebanyak $28 \mathrm{KK}$ atau $70 \% \mathrm{KK}$ yang termasuk dalam kriteria kaya dan $12 \mathrm{KK}$ atau $30 \% \mathrm{KK}$ petani kelapa kelapa sawit termasuk dalam kriteria cukup. Dari pendapatan setara beras dapat disimpulkan bahwa petani kelapa kelapa sawit di Desa
Merarai Satu Kecamatan Sungai Tebelian Kabupaten Sintang dapat dikatakan sejahtera.

\section{SIMPULAN}

Adanya perkebunan kelapa kelapa sawit di Desa Merarai Satu telah memberikan perubahan pada tingkat pendapatan dan kesejahteraan petani kelapa kelapa sawit dimana Pendapatan petani kelapa kelapa sawit setelah lunas kredit dengan PT. SDK III lebih tinggi yaitu sebesar Rp 56.565.905,29 per petani per tahun per hektar atau sebesar Rp 4.713.825,44 per petani per bulan per hektar dibandingkan dengan pendapatan petani kelapa kelapa sawit sebelum lunas kredit yaitu sebesar Rp 31.847.722,7 per petani per tahun per hektar atau sebesar Rp 2.653.976,89 per petani per bulan per hektar sehingga berpengaruh pada tingkat pendapatan dan kesejahteraan petani kelapa kelapa sawit Desa Merarai Satu. Terdapat perbedaan yang signifikan trhadap tingkat pendapatan petani kelapa kelapa sawit 
Desa Merarai Satu sebelum dan setelah lunas kredit.

Berdasarkan pendapatan setara beras kilogram per kapita per tahun, rata-rata kehidupan petani kelapa kelapa sawit desa Merarai Satu sebelum lunas kredit termasuk dalam masyarakat cukup yaitu sebesar $32 \mathrm{KK}$ atau $80 \%$ dan setelah lunas kredit termasuk dalam masyarakat kaya yaitu sebesar $28 \mathrm{KK}$ atau $70 \%$.

\section{DAFTAR PUSTAKA}

Badan Pusat Statistik Provinsi Kalimantan Barat.2013. Kalimantan Barat Dalam Angka, Pontianak.

Soekanda. 2001. Kelapa Kelapa sawit. (Online). www.wikimu.com, Diakses Pada 26 November 20014.

Sajogyo. 1982. Menelaah Garis Kemiskinan. Makalah pada Lokakarya Metode Kaji Tindak, Proyek P4K, Cikarang.

1977. Garis Miskin dan Kebutuhan Minimum Pangan. Lembaga Penelitian Sosiologi Pedesaan (LPSP). IPB. Bogor. 